\title{
TRANSPORTE PÚBLICO URBANO: ESTUDO DE MOBILIDADE SOBRE FEIRA DE SANTANA
}

\author{
Ângela Terezinha Ferreira Vieira ${ }^{1}$ e Ana Rita Sulz de A. Campos ${ }^{2}$ \\ 1. Bolsista PROBIC/UEFS, Graduanda em Engenharia Civil, Universidade Estadual de Feira de Santana, \\ e-mail: angelavieira0110@ hotmail.com \\ 2. Orientador, Departamento de Letras e Artes, Universidade Estadual de Feira de Santana, \\ e-mail: sulz@uefs.br
}

PALAVRAS-CHAVE: mobilidade; transporte público; transporte urbano.

\section{INTRODUÇÃO}

O transporte público e coletivo deve atender a todos os cidadãos sem qualquer distinção, e deve ser proporcionado pelo poder público. Considerado serviço essencial, de acordo com a Constituição Federal de 1988, cabe ao município a prestação desse serviço e responsabilidade mesmo quando oferecido por empresas privadas, através da concessão. $\mathrm{Na}$ última década, com os incentivos dos governos e a facilidade de crédito para aquisição de automóveis, deu-se início a inúmeros problemas no que tange a mobilidade urbana, especialmente nos centros de maior densidade populacional. Com vias não oferecendo suporte para tal explosão os proprietários dos automóveis passam a pressionar os órgãos gestores para investir em infraestrutura viária, como construção de viadutos e obras de alargamento de ruas.

De acordo com Silva e Ferraz (1991, p.4), o automóvel consome dez vezes mais o espaço viário que um ônibus, já que o automóvel transporta 1,5 passageiros em média e ocupa cerca de 7,5 $\mathrm{m}^{2}$ do espaço viário, logo, cada passageiro ocupa aproximadamente $5 \mathrm{~m}^{2}$ de uma via. Um ônibus ocupa cerca $30 \mathrm{~m}^{2} \mathrm{e}$ transporta uma média de 60 passageiros, portanto, cada passageiro ocupa uma área de $0,5 \mathrm{~m}^{2}$. Esses dados mostram como o uso do automóvel agrava o panorama já caótico do trânsito na maioria dos centros urbanos do Brasil, situação observada em Feira de Santana, cujo aumento de congestionamentos nas regiões de maior circulação de veículos e atuais medidas adotadas para enfrentar esta problemática, acirram as discussões sobre mobilidade urbana na segunda cidade mais populosa da Bahia.

A implantação do transporte público de qualidade acompanhada de campanhas de incentivo para o seu uso pode trazer benefícios para toda a sociedade, a exemplo da diminuição do número de acidentes, minimização de congestionamentos no trânsito, redução da poluição atmosférica e sonora, entre outros, considerando que parte dos usuários de automóveis deverá migrar para o uso do transporte público, além da consequente melhoria na qualidade de vida.

\section{MATERIAL E MÉTODOS OU METODOLOGIA}

Para melhor identificação e compreensão da mobilidade urbana em Feira de Santana, inicialmente foram empregadas técnicas de pesquisa documental e bibliográfica, com o objetivo de construir o conteúdo a ser analisado. No levantamento dos dados referentes ao 
uso do transporte público urbano e suas consequências, foram utilizados como base para a pesquisa, trabalhos científicos publicados, livros que abordam a temática e o conhecimento de dados disponibilizados por órgãos da cidade de Feira de Santana.

\section{RESULTADOS ALCANÇADOS E DISCUSSÃO}

No Brasil, o uso do transporte individual é priorizado. Segundo o relatório realizado pelo Instituto de Energia e Meio Ambiente (IEMA), divulgado em setembro de 2016, existe grande discrepância entre o uso de automóveis, motocicletas e ônibus entre os anos de 1990 até 2014. O automóvel é o meio de transporte mais utilizado, seguido da motocicleta e por último o uso do ônibus, como mostra o gráfico 1.

\section{Gráfico 1. EVOLUÇÃO DA INTENSIDADE DE USO DA FROTA DE VEÍCULOS NO TRANSPORTE DE PASSAGEIROS NO BRASIL (1990-2014)}

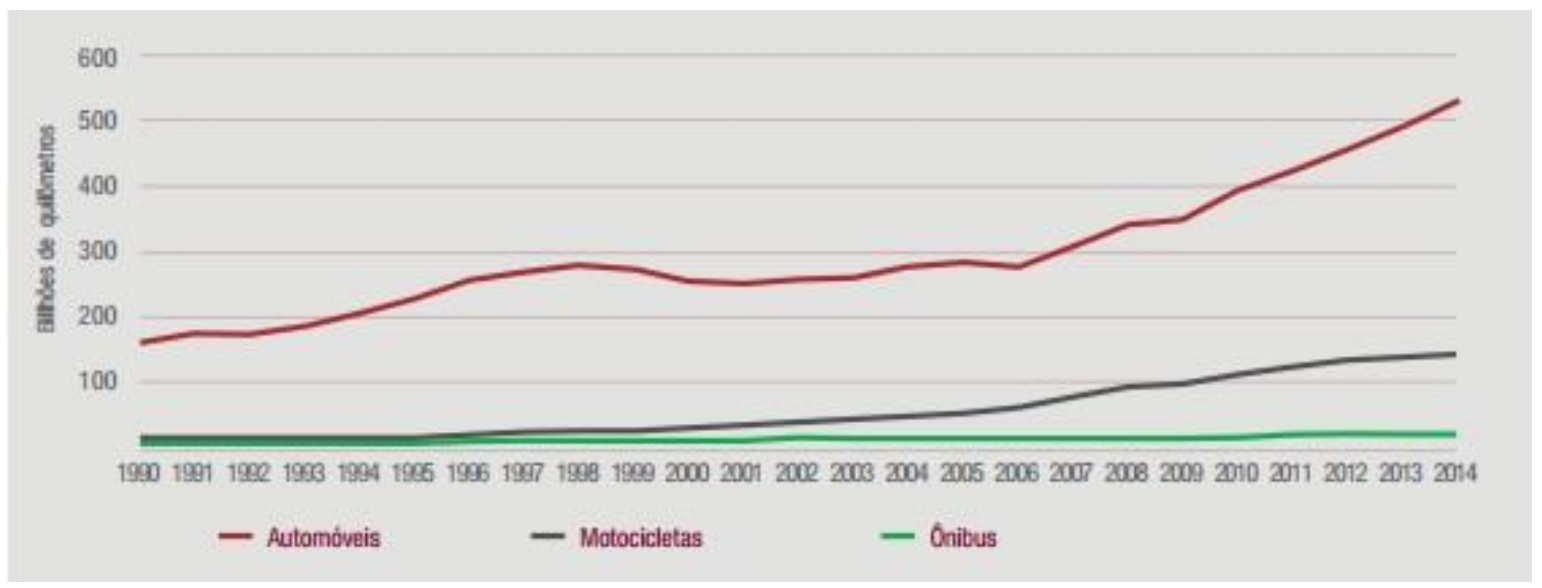

Fonte: Sítio do Integra - Associação de empresas de transporte de Salvador ${ }^{1}$

De acordo com o Instituto de Pesquisa Econômica Aplicada (IPEA), o sistema de mobilidade urbana dos grandes centros brasileiros é caracterizado pelo intenso uso do transporte individual motorizado. Nas cidades com população acima de 60.000 habitantes, a frota circulante no ano de 2007 era de 20 milhões de veículos, sendo 15,2 milhões automóveis e veículos comerciais leves $(75,2 \%)$. Nas áreas urbanas desses municípios são realizados, por dia, cerca de 148 milhões de deslocamentos. Diante de aspectos relacionados ao transporte público e o automóvel no Brasil, podemos citar como vantagens e desvantagens:

\section{Vantagens e desvantagens do uso do transporte público no Brasil.}

- VANTAGENS: Pode ser uma alternativa para desafogar o trânsito, reduz a probabilidade de acidentes de trânsito, meio de transporte mais econômico que o

\footnotetext{
${ }^{1}$ Disponível em: http://www.integrasalvador.com.br/emissao-de-co2-de-carros-e-motos-cresce-192-no-brasil-dizpesquisa/ Acesso 12 de maio de 2016
} 
privado, menor ocupação do espaço urbano, facilita a mobilidade do trânsito dentro das cidades e seu uso disseminado pode contribuir para a conservação das cidades.

- DESVANTAGENS: Superlotação a que está sujeito, principalmente nos horários de pico, tempo gasto nos pontos e estações, falta de segurança nos pontos de espera, inflexibilidade da rota e dos horários, tempo gasto com caminhadas até os pontos ou estações e impossibilidade de transportar cargas.

\section{Vantagens e desvantagens do uso do automóvel no Brasil.}

- VANTAGENS: Tempo de viagem mais curto (relacionado ao transporte público), maior flexibilidade em horários e possibilidade de transportar cargas.

- DESVANTAGENS: Alto custo para adquirir e para manter, dificuldade para estacionar nas grandes cidades, grande responsável pela emissão de gases poluentes e ocupa muito espaço nas vias.

\section{Características dos congestionamentos em Feira de Santana}

Os congestionamentos provocam desperdício de tempo e dinheiro além de outros danos. Para Schweitzer e Taylor (2008) existem dois fatores básicos que afetam o trânsito e causam congestionamento: excesso de veículos em horários específicos e acidentes ou ocorrências que podem bloquear a pista. Os congestionamentos que ocorrem na cidade de Feira de Santana, além de se enquadrar nos fatores citados por Schweitzer e Taylor, apresentam características ligadas a outros fatores:

- Presença significante de veículos pesados: A cidade tem o mais importante entroncamento rodoviário do Norte e Nordeste do país e é cortada por importantes rodovias, ocasionando um grande número de veículos pesados trafegando pela mesma. Os veículos pesados apresentam um desempenho relativamente baixo e menor que os veículos leves, assim os automóveis leves são obrigados a realizar manobras de mudança de faixa constantemente, ocasionando grandes congestionamentos na cidade.

- Fator de hora de pico: A variação do fluxo de tráfego é medida durante o período de uma hora em que é observado o maior volume de tráfego. A organização da nossa sociedade proporciona que muitas pessoas se desloquem no mesmo horário, logo, muitas vezes o congestionamento é inevitável.

\section{Dados relacionados ao número de acidentes em Feira de Santana:}

Feira de Santana apresentou substancial aumento no número de acidentes de trânsito com óbitos a partir do ano de 2004. No ano de 2007 a cidade teve quantidade de acidentes por 100 mil habitantes maior que a média nacional, segundo dados disponibilizados pelo Ministério da Saúde - DATASUS (tabela 1). 
TABELA 1. NÚMERO DE ÓBITOS EM ACIDENTES DE TRANSITO. COMPARATIVO DE FEIRA DE SANTANA COM A MÉDIA NACIONAL (1999-2014)

\begin{tabular}{|c|c|c|}
\hline & FEIRA DE SANTANA-BA & MÉDIA NACIONAL \\
\hline 1999 & 15,00 ÓBITOS $/ 100 \mathrm{mil} \mathrm{hab.}$ & 18,04 ÓBITOS/100 mil hab. \\
\hline 2000 & 12,68 óBITOS/100 mil hab. & 17,08 ÓBITOS $/ 100 \mathrm{mil}$ hab. \\
\hline 2001 & 5,71 ÓBITOS/100 mil hab. & 17,71 ÓBITOS $/ 100 \mathrm{mil}$ hab. \\
\hline 2002 & 5,64 óBITOS $/ 100$ mil hab. & 18,76 ÓBITOS $/ 100 \mathrm{mil}$ hab. \\
\hline 2003 & 4,56 ÓBITOS $/ 100$ mil hab. & 18,74 ÓBITOS $/ 100 \mathrm{mil}$ hab. \\
\hline 2004 & 4,89 ÓBITOS $/ 100$ mil hab. & 19,60 ÓBITOS $/ 100 \mathrm{mil}$ hab. \\
\hline 2005 & 9,26 ÓBITOS $/ 100 \mathrm{mil}$ hab. & 19,54 ÓBITOS $/ 100 \mathrm{mil}$ hab. \\
\hline 2006 & 16,76 óBITOS $/ 100$ mil hab. & 19,47 ÓBITOS $/ 100 \mathrm{mil}$ hab. \\
\hline 2007 & 21,50 óBITOS $/ 100$ mil hab. & 19,46 ÓBITOS $/ 100 \mathrm{mil}$ hab. \\
\hline 2008 & 15,91 óBITOS $/ 100$ mil hab. & 20,18 ÓBITOS $/ 100 \mathrm{mil}$ hab. \\
\hline 2009 & 17,44 ÓBITOS/100 mil hab. & 19,63 ÓBITOS $/ 100 \mathrm{mil}$ hab. \\
\hline 2010 & 22,64 óBITOS $/ 100$ mil hab. & 22,46 ÓBITOS $/ 100 \mathrm{mil}$ hab. \\
\hline 2011 & 22,22 óBITOS $/ 100 \mathrm{mil} \mathrm{hab.}$ & 22,48 ÓBITOS $/ 100 \mathrm{mil}$ hab. \\
\hline 2012 & 23,06 ÓBITOS $/ 100 \mathrm{mil}$ hab. & 23,10 ÓBITOS $/ 100 \mathrm{mil}$ hab. \\
\hline 2013 & 17,82 óBITOS $/ 100$ mil hab. & 20,12 ÓBITOS $/ 100 \mathrm{mil}$ hab. \\
\hline
\end{tabular}

Fonte: DATASUS

O poder público municipal, de acordo com o inciso $\mathrm{V}$ do artigo 30 da Constituição Federal e 1988, é o responsável primário pelo transporte público. Deste modo, cabe ao município "organizar e prestar, diretamente ou sobre regime de concessão ou permissão, os serviços públicos de interesse local, incluído o de transporte coletivo, que tem caráter essencial." Tal dispositivo da constituição oferece ao município a liberdade de encolher a forma como o serviço de transporte público será ofertado.

A prefeitura de Feira de Santana segue a tendência nacional, na qual o sistema de transporte público é concessionado ou permitido para uma ou mais empresas, no caso de Feira de Santana, duas empresas. A licitação do serviço de transporte público, não isenta o município de obrigações, como investimento em infraestrutura, fiscalização, planejamento e realização de cálculo tarifário.

\section{Características do transporte público em Feira de Santana:}

Hoje a cidade de Feira de Santana está passando pela implantação de um novo sistema de transporte público, o BRT ( Bus Rapid Transit). O BRT se diferencia do ônibus convencional por uma série de características, entre elas podemos citar: corredores exclusivos, alta capacidade de usuários, a forma de acesso (estação). De acordo com o Jornal Acorda Cidade, em reportagem divulgada em janeiro de 2017, alguns usuários do transporte público de Feira de Santana estavam insatisfeitos com a realidade do transporte na cidade, e entre as reclamações citadas estão o aumento da tarifa de ônibus, demora nos pontos de ônibus, falta de ventilação e segurança.

\section{CONSIDERAÇÕES FINAIS (ou Conclusão)}

Os estudos realizados nessa pesquisa mostram como o uso do transporte público oportuna inúmeros benefícios para a sociedade. Quando o transporte individual é substituído 
pelo transporte público coletivo esses benefícios são ainda maiores. Com base no exposto e discutido ao longo da pesquisa, foi possível visualizar que o cenário atual é de priorização do transporte individual. Essa priorização tem relação direta com a cultura do status que o automóvel proporciona, incentivo do governo, desde duplicação das vias, até subsídios para adquirir transportes individuais.

Para que ocorra um maior uso do transporte público coletivo é necessário que a população consiga visualizar as vantagens que o seu uso oferece, para alcançar o objetivo é necessário um transporte mais otimizado que apresente mais eficiência e eficácia.

\section{REFERÊNCIAS}

BRASIL. Constituição (1988). Constituição da República Federativa do Brasil. Inciso V, artigo 30.

DOWNS, Anthony. Still stuck in traffic: coping with peak-hour congestion. Brookings Intitution Press: Washington, D.C., 2004.

IEMA - INSTITUTO DE ENERGIA E MEIO AMBIÊNTE (2016). Emissões de GEE do Setor de Energia, Processos Industriais e Uso de Produtos. Documento de Análise, setembro de 2016.

IPEA - INSTITUTO DE PESQUISA ECONÔMICA APLICADA (2011). A Mobilidade Urbana no Brasil. Comunicados do Ipea, maio de 2011.

JOSÉ, P. População reclama do aumento de tarifa de ônibus e diz que qualidade do serviço é ruim. Acorda Cidade. 16 de janeiro de 2017. Disponível em: $<$ http://www.acordacidade.com.br/imprimir/171515/populacao-reclama-do-aumento-da-tarifa-deonibus-e-diz-que-qualidade-do-servico-e-ruim.html> Acesso em: 21 de março de 2017.

SILVA, Antônio Nelson Rodrigues da; FERRAZ, Antônio Clóvis Pinto. Transporte público urbano: operação e administração. Notas de aula. São Carlos: Escola de Engenharia de São Carlos - EESC USP, 1991.

SCHWEITZER, Lisa; TAYLOR, Brian D. Just Pricing: the distributional effects of congestion pricing and sales taxes. 25 sep 2008. 